\title{
Г.Т. Дягилев
}

\section{Эпизоотологическая классификация неблагополучных пунктов по сибирской язве в Республике Саха (Якутия)}

Ключевые слова: эпизоотия, сибирская язва, неблагополучные пункты, манифестные, неманифестные, классификации

В настоящей работе представлены данные неблагополучных пунктов по сибирской язве животных, зарегистрированных в Якутии с 1811 по 1993 гг. По природно-климатическим, почвенным особенностям агроклиматических зон, сельскохозяйственной и промышленной специализации районов территория республики разделена на пять экономических зон, на территории которых зарегистрированы 739 случаев вспышек сибирской язвы среди домашних и диких животных в 244 населенных пунктах, в 29 административных районах. Из 739 вспышек сибирской язвы 13,5\% - регистрировались однократно, 45,7\% вспышки сибирской язвы повторялись через год, 14,3\% - через 2 года, 6,4\% через 3 года, 6,1\% - через 4 года, 4,9\% - через 5 лет, 1,6\% - через 6 лет, 4,5\% через 7 лет, 1,9\% - через 8 лет, 2,6\% - через 9 лет, 1,9\% - через 10 лет, а также 10,1\% - больше 11 лет. За 206 лет наблюдений выяснилось, что повторные вспышки сибирской язвы в Республике Саха (Якутия) возникали 2 года подряд в одном и том же населенном пункте составляет 5,81\%, 3 года подряд $-3,8 \%, 4$ года подряд $-3,8 \%$, от 4 до 6 раз $-5,1 \%$, от 7 до 9 раз $-2 \%$, от 10 до 18 раз 1,2\%. Это свидетельство того, что уровень повторных (подряд) эпизоотий на территории республики был высокий до середины 60 годов прошлого столетия. При этом число повторных случаев заболеваний более чем 6 раз превышает однократные. В районах расположенных в Центральной зоне вспышки сибирской язвы не регистрировались от 42 до 85 лет, в районах Западной зоны от 25 до 64 лет, в районах Арктической зоны от 30 до 141 лет, в районах Восточной зоны от 44 до 74 лет, а также в Южной зоне 49 лет. На основе анализа полученных результатов установлено, что на территории Республики 
Саха (Якутия) 243 (99,6\%) неблагополучных пункта относятся к стационарным, в которых сибирская язва повторялась различные промежутки времени, и 1 является новым (Эвено-Бытантайский район), в котором болезнь регистрировалась 1 раз. Оздоровленных пунктов нет, так как вакцинацию в неблагополучных пунктах проводят постоянно.

\section{G.T. Dyagilev \\ Epizootological classification of the anthrax adverse areas in the Sakha Republic (Yakutia)}

Key words: epizooty, anthrax, adverse areas, overt, non-overt, classification.

In the present work, the data collected at the adverse areas with the Siberian anthrax animals registered in the Sakha Republic (Yakutia) from 1811 to 1993 is presented.

The territory of the Republic is divided into five economic zones based on the natural and climatic, soil characteristics of agroclimatic zones, and agricultural and industrial specialization of the regions, where in 244 settlements and 29 administrative districts 739 cases of anthrax outbreaks in domestic and wild animals were registered. Of the 739 anthrax outbreaks, 13.5\% were recorded once, 45.7\% recurred past the year mark, $14.3 \%$ recurred in 2 years, $6.4 \%$ in 3 years, $6.1 \%$ in 4 years, $4.9 \%$ in 5 years, $1.6 \%$ in 6 years, $4.5 \%$ in 7 years, $1,9 \%$ in 8 years, $2.6 \%$ in 9 years, $1.9 \%$ in 10 years, and $10.1 \%$ in more than 11 years.

Over the 206 years of observation, it was found that the percentage of repeated outbreaks of anthrax in the Sakha Republic (Yakutia) occurred for 2 consecutive years in the same locality is $5.81 \%, 3$ consecutive years $-3.8 \%$, 4 consecutive years $3.8 \%$, from 4 to 6 times $-5,1 \%$, from 7 to 9 times - 2\%, from 10 to 18 times-1,2\%. This reveals that the level of repeated (successively) epizootics in the territory of the Republic was high up to the mid-1960s. At the same time the number of repeated cases exceeded a single occurrence more than 6 times. Anthrax outbreaks have not been recorded for 42 to 85 years in the Central regions, in the Western regions for 25 
to 64 years, in the Arctic regions for 30 to 141 years, in the Eastern region for 44 to 74 years, and in the Southern region for 49 years. Based on the analysis of the obtained results, 243 (99.6\%) of the adverse areas on the territory of the Republic of Sakha (Yakutia) are rated as stationary ones, in which the anthrax occurred at various intervals, and 1 is a new place (Eveno-Bytantai district) in which the disease was registered 1 time. There are no rehabilitated places, as vaccination in adverse areas is carried out constantly.

Дягилев Григорий Тимофеевич, кандидат ветеринарных наук, старший научный сотрудник лаборатории ветеринарной биотехнологии ФГБНУ «Якутский научно-исследовательский институт сельского хозяйства»; 677001, Республика Саха (Якутия), г. Якутск, ул. Бестужева-Марлинского, 23/1; e-mail: yniicx@mail.ru

Grigory T. Dyagilev, Candidate of Veterinary Science, Senior Research Scientist of Veterinary Biotechnology Laboratories, The Yakut Scientific Research Institute of Agriculture of the Russian Academy of Sciences; 23/1, BestuzhevMarlinsky St., Yakutsk, Republic of Sakha (Yakutia), 677001, Russia; e-mail: yniicx@mail.ru

\section{Введение}

Сибирская язва (Anthrax) уникальная инфекционная болезнь животных и человека. Однажды возникнув в какой-либо местности, она может укореняться, сохраняя на многие десятилетия угрозу повторных вспышек. [1]

Источником инфекции является зараженный организм восприимчивого животного и почва, где споры B.anthracis при определенных условиях способны длительно сохраняться и размножаться, что создает постоянную угрозу инфицирования животных и людей. [2]

По динамике активности неблагополучные пункты по сибирской язве разделяются на 3 категории: активно действующие, в которых эпизоотии сибирской язвы регистрируются с интервалом в 1-2 года; рецидивирующие, в 
которых за последние 10 лет эпизоотии сибирской язвы повторялись 2-3 раза; неактивные, в котором эпизоотия сибирской язвы регистрировалась 1 раз и в течение 10 лет не повторялась.

Многообразие вариантов проявления эпизоотологической и эпидемиологической активности неблагополучных по сибирской язве пунктов требует создания рациональной научно обоснованной их классификации. [2]

Поэтому эпизоотологической классификации неблагополучных по сибирской язве пунктов следует уделять особое внимание, так как только на её основе можно выделить очаги с различной активностью. К настоящему времени известью несколько классификаций неблагополучных пунктов по сибирской язве: А.С. Коротич (1968), Э.Н. Шляхов (1968), Б.Л. Черкасский (1968, 2002), Л.И. Погребняк (1974), Н.Г. Ипатенко, В.С. Зелепукин (1996) [2].

Территория Республики Саха (Якутия) характеризуется эпизоотически неблагоприятной эпизоотической обстановкой по сибирской язве с сохранением предпосылок для ее ухудшения, что обусловлено большим количеством неблагополучных пунктов и систематическим характером проявления инфекции. [4,5]

Зная динамику эпизоотий сибирской язвы можно планировать лечебнопрофилактические мероприятия с меньшими финансовыми затратами. Нахождение в почве микробов сибирской язвы не гарантирует полное благополучие территории от новых эпизоотий сибирской язвы независимо от срока давности.

Цель работы - изучить кратность, периодичность проявления эпизоотологической активности стационарно неблагополучных пунктов по сибирской язве и составить эпизоотологическую классификацию неблагополучных пунктов по сибирской язве животных в Республике Саха (Якутия).

Материал и методика исследования. При составлении эпизоотологической классификации неблагополучных пунктов по сибирской 
язве животных использованы данные официальной отчетности Управления ветеринарии Якутской области, годовые отчеты, служебные информации НКЗ Якутской АССР, Министерства сельского хозяйства Республики Саха (Якутия), Департамента ветеринарии Республики Саха (Якутия) о сроках регистрации эпизоотий сибирской язвы, а также материалы собственных исследований эпизоотических очагов сибирской язвы. [4,5]

Для оценки характера проявления эпизоотических очагов изучали и анализировали уровни эпизоотического неблагополучия и распространенность по экономическим зонам, территориальную прирученность и продолжительность эпизоотического процесса, кратности и периодичности повторяемости вспышек на уровне населенных пунктов с применением метода хронологически последовательного сравнительно-исторического описания неблагополучных пунктов, обследования и анализа сроков последних вспышек сибирской язвы по районам. [5]

Эпизоотическое исследование проведено в соответствии с методическими рекомендациями «Изучение эпизоотической ситуации инфекционных болезней сельскохозяйственных животных в области (крае. АССР)». [3]

Результаты исследований. В прошлом сибирская язва встречалась почти во всех районах Якутской АССР, в которой более поражены территории центральной и западной Якутии, примыкающие к рекам Лена, Алдан, Вилюй и Амга.

Первые сведения о возникновении сибирской язвы в Якутии относятся к 1811 г., когда в Колымском округе пало 175 лошадей и 8 гол. крупного рогатого скота [5]. Последняя эпизоотия сибирской язвы на территории Республики Саха (Якутия) зарегистрирована в 1993 г. в Мирнинском районе. [5]

Исследования эпизоотий сибирской язвы на территории республики проведены за 206-летний период (1811-2017 гг.) в 29 районах. 
Таблица 1 - Показатели кратности и периодичности проявления эпизоотологической активности стационарно неблагополучных пунктов на территории Республики Саха (Якутия) с 1811 по 2017 гг.

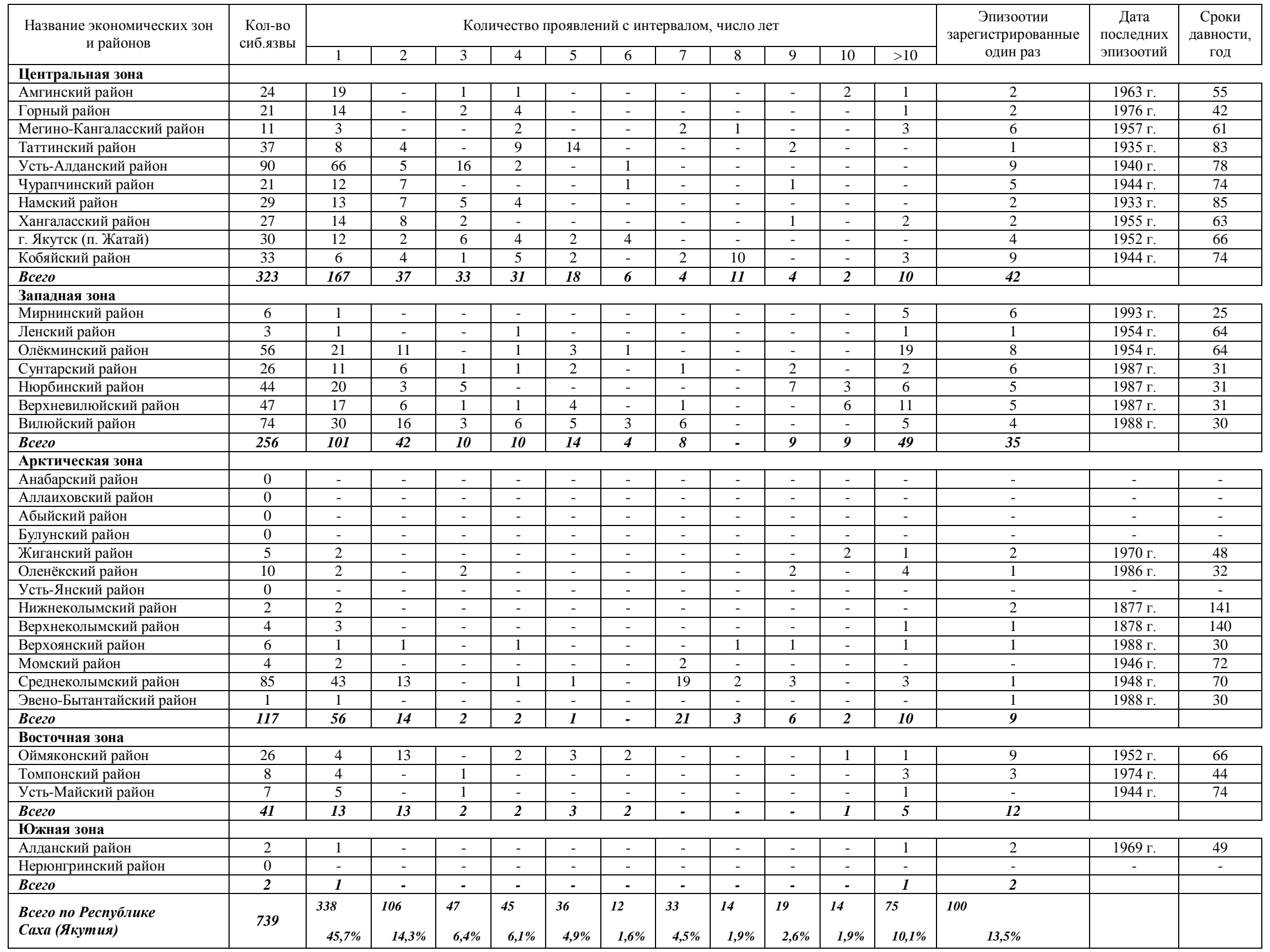


Республика Саха (Якутия) поделена на пять экономических зон, на территории которых зарегистрированы 739 случаев вспышек сибирской язвы среди домашних и диких животных в 244 населенных пунктах и в 29 административных районах.

Одной из главных причин широкомасштабного проявления сибирской язвы - это отсутствие и нехватка ветеринарных специалистов, громадные тундровые пространства на севере, большое количество лесных и болотистых местностей - эти природные условия в сочетании с неудовлетворительным состоянием населенных пунктов способствовали ежегодному развитию эпизоотий сибирской язвы. [5] Ранее исследованным данным спорадические случаи заболевания и эпизоотические вспышки болезни зарегистрировались в Олёкминском (1946, 1950, 1951 гг.), Алданском (1957), Намском (1948, 1949, 1950, 1951), Хангаласском (1955), Верхневилюйском (1955, 1957), Сунтарском (1951, 1955, 1956), Оленёкском (1957), Томпонском (1957) районах. Затем в течении с 1961 по 1962, с 1964 по 1968, с 1978 по 1979, с 1981 по 1985 гг., эпизоотии сибирской язвы на территории республики не регистрировались. [4, $5]$.

По нашим данным с 1970 по 1993 гг. эпизоотии сибирской язвы были зарегистрированы у КРС, оленей и дикой фауне в Западной зоне республики (Оленёкский (1970, 1986), Вилюйский (1970, 1987, 1988), Нюрбинский (1970, 1987), Сунтарский (1987), Верхневилюйский (1987), Мирнинский (1970, 1993) районы), а также небольшие эпизоотии и спорадические случаи заболевания животных регистрировались в Томпонском, Горном $(1974,1976)$ и Жиганском (1980) районах [4].

Из 739 вспышек сибирской язвы: 13,5\% - регистрировались однократно, 45,7\% вспышки сибирской язвы повторялись через год, 14,3\% - через 2 года, 6,4\% - через 3 года, 6,1\% - через 4 года, 4,9\% - через 5 лет, 1,6\% - через 6 лет, 4,5\% - через 7 лет, 1,9\% - через 8 лет, 2,6\% - через 9 лет, 1,9\% - через 10 лет, а также 10,1\% - больше 11 лет. 
По отчетным данным управлений ветеринарии повторные вспышки сибирской язвы в Якутии за 206 лет возникали 2 года подряд в одном и том же населенном пункте, что составляет 5,81\%, 3 года подряд -3,8\%, 4 года подряд 3,8\%, от 4 до 6 лет подряд - 5,1\%, от 7 до 9 лет подряд -2\%, от 10 до 18 лет подряд - 1,2\%. Это свидетельствует что уровень повторных (подряд) эпизоотий на территории республики был высокий до середины 60 годов прошлого столетия, повторные случаи заболеваний превышали однократные в 6 раз (табл. 1).

При анализе последних вспышек эпизоотий сибирской язвы среди животных видно, что в районах расположенных в Центральной зоне вспышки сибирской язвы не регистрировались от 42 до 85 лет, в районах Западной зоны от 25 до 64 лет, в районах Арктической зоны от 30 до 141 лет, в районах Восточной зоны от 44 до 74 лет, а также в Южной зоне 49 лет.

По результатам исследований активности стационарных неблагополучных пунктов на территориях 4 экономических зон отмечаются появление новых эпизоотий сибирской язвы, начиная с 11 года от первой регистрации вспышки.

На основе анализа полученных результатов установлено, что на территории Республики Саха (Якутия) 243 (99,6\%) населенных пунктов относятся к стационарно неблагополучным пунктам и зарегистрирован 1 новый неблагополучный пункт в Эвено-Бытантайском районе. Оздоровленных пунктов нет, так как вакцинацию в неблагополучных пунктах проводят постоянно.

Максимальное количество вспышек сибирской язвы и стационарно неблагополучных населенных пунктов выявлены в районах, относящихся к Центральной, Западной зонах, а также из Арктической зоны Среднеколымский район, из Восточной зоны - Оймяконский район.

Анализ эпизоотолого-эпидемиологического мониторинга показывает, что 43,7\% возникновения сибирской язвы зарегистрированы на территории 
Центральной зоны, 34,6\% Западной зоне, 15,8\% Арктической зоне, 5,5\% Восточной зоне, 0,27\% Южной зоне. Наибольшее количество неблагополучных пунктов и очагов сибирской язвы находятся в районах, примыкающих к рекам Лена, Вилюй и Алдан (Усть-Алданский, Якутский, Кобяйский, Таттинский, Намский, Олёкминский, Верхневилюйский, Вилюйский, Нюрбинский, Среднеколымский, Оймяконский).

Классификация неблагополучных пунктов по сибирской язве животных в Республике Саха (Якутия) за 1811-2017 гг.:

1. Старые 244 (100\%).

2. Неманифестные (неактивные) $243(99,6 \%)$.

3. Новые (вновь образовавшиеся) 1 (0,4\%).

Заключение. Таким образом, в результате проведенных исследований кратности и периодичности проявления активности эпизоотологических очагов сибирской язвы за 206-летний (1811-2017 гг.) период и уточнением периодов благополучия после последних вспышек сибирской язвы по районам (от 25 лет до 141 лет) неблагополучные пункты по сибирской язве в Республике Саха (Якутия) можно классифицировать на старые, неманифестные и новые.

\section{Библиографический список}

1. Бакулов, И. А. Сибирская язва (антракс): новые страницы в изучении «старой болезни» [Текст] / И. А. Бакулов, В. А. Гаврилов, В. В. Селиверстов. Владимир: Посад, 2001. - С. 8, 61-63. // Bakulov, I. A. Anthrax: anthrax: new pages instudying the "old disease" [Text] / I. A. Bakulov, V. A. Gavrilov, V. V.Seliverstov. - Vladimir: Posad, 2001. - p. 8, 61-63.

2. Барышников, П. И. Сибирская язва животных в Алтайской крае[Текст]: монография / П. И. Барышников, Г. А. Федорова, И. М. Гатилов; Алт. гос. аграр. ун-т. - Барнаул, 2007. - С. 28. // Baryshnikov, P. I. Anthrax of animals in the Altaisky krai [Text]: monograph / P. I. Baryshnikov, G. A. Fedorova, I. M. Gatilov;Alt. state agrarian un-t - Barnaul, 2007. - p. 28. 
3. Джупина, С. И. Методы эпизоотологических исследований [Текст]: метод. рекомендации / С. И. Джупина, А. А. Колосов; Рос. акад. с.-х. наук, Сиб. отд-ние, Ин-т эксперимент. ветеринарии Сибири и Дальнего Востока. Новосибирск, 1991. - 60 с. // Jupina, S.I. Methods of Epizootic Research[Text]: method. recommendations / S.I. Jupina, A.A. Kolosov; Ros. acad. s.-.Sciences, Sib. Institute, Institute of Experiments. veterinary science of Siberia and FarEast. Novosibirsk, 1991. - 60 p.

4. Дягилев, Г. Т. Эпизоотологическая характеристика сибирской язвы с 1811 по 1993 года в Республике Саха (Якутия) [Текст] / Г. Т. Дягилев, М. П. Неустроев // Актуальные вопросы ветеринарной биологии. - 2012. - №1. - С. 33-36. // Dyagilev, G.T. An Epizootological Characteristic of the Siberian anthrax from 1811 to 1993 in the Sakha Republic (Yakutia) [Text] / G.T. Dyagilev,M.P. Neustroev // Actual questions of veterinary biology. - 2012. -№1. - P. 33-36.

5. Дягилев, Г. Т. К истории сибирской язвы в Якутской области в ХIX веке. / Г. Т. Дягилев, М. П. Неустроев // Актуальные вопросы ветеринарной биологии. - 2010. - №4. - С. 3-7. // Dyagilev, G.T. To the history of anthrax in the Yakutsk region in XIX century. / G.T. Dyagilev, M.P. Neustroev // Actual questions of veterinary biology. - 2010. - №4. - P. 3-7.

6. Огнев, Н. И. Ветеринарная служба в Якутии с 1853 по 1919 гг. / Н. И. Огнев // Ученые записки Якутского государственного университета. - 1962. Вып. 13. - С. 87-97. // 6. Ognev, N. I. Veterinary service in Yakutia from 1853 to 1919. /N.I. Ognev // Scientific notes of Yakutsk State University. -1962. - Issue. 13. P. 87-97. 